\title{
Night Cream Containing Melatonin, Carnosine and Helichrysum italicum Extract Helps Reduce Skin Reactivity and Signs of Photodamage: Ex Vivo and Clinical Studies
}

\author{
Corinne Granger · Anthony Brown · Sonia Aladren · Mridvika Narda
}

Received: August 4, 2020 / Published online: September 11, 2020

(C) The Author(s) 2020

\section{ABSTRACT}

Introduction: Extrinsic factors, such as solar radiation and urban pollution, cause damage that alters the structure, function and appearance of skin. The aim of this study was to determine the ability of a night cream containing melatonin, carnosine and Helichrysum italicum extract (referred to here as Night Cream) to reduce extrinsic skin damage, and to evaluate the efficacy of this Night Cream to reduce clinical signs of age and photodamage under normal conditions of use.

Methods: Recovery from extrinsic damage was assessed by exposing human skin explants to ultraviolet (UV) A, infrared light, blue light or pollution and then treating the stress-exposed explants with Night Cream. Markers of

Anthony Brown is an External Consultant to ISDIN

Digital Features To view digital features for this article go to https://doi.org/10.6084/m9.figshare.12876359.

C. Granger · S. Aladren · M. Narda $(\bowtie)$

Innovation and Development, ISDIN, Barcelona, Spain

e-mail: mridvika.narda@isdin.com

A. Brown

Barcelona, Spain oxidative stress were examined by immunohistochemistry. Anti-aging and calming properties were determined in four single-center, open-label trials involving 117 individuals. Subjects applied Night Cream to their face once nightly for up to 12 weeks. Improvements in clinical signs of age and photodamage, and reduction of lactic acid-induced stinging were evaluated by investigator assessment and subject selfassessment.

Results: Night Cream significantly reduced oxidative stress in human skin ex vivo. Clinically, hydration (+ 64.4\%; $p<0.05)$ and transepidermal water loss (TEWL) values $(-10.0 \% ; p<0.05)$ were improved within $1 \mathrm{~h}$ of use. Wrinkle counts were reduced by up to $18.9 \%(p<0.05)$, and brown and UV spot numbers by $5.5 \% \quad(p<0.05)$ and $13.2 \%$ $(p<0.05)$, respectively. Lactic acid-induced stinging was significantly reduced within 7 days of use, with $86.7 \%$ of subjects reporting that their skin felt calmer.

Conclusion: These findings suggest that Night Cream reduces skin damage caused by environmental factors and that its nightly use can improve clinical signs of aging with additional skin calming benefits.

Keywords: Carnosine; Melatonin; Photoaging; Skin aging; Skin calming 


\section{Key Summary Points}

Why carry out this study?

Photodamage from sun and other extrinsic factors, such as pollution, cause skin damage and irritation.

The aim of this study was to validate the ability of a night cream containing naturally occurring substances for the treatment of skin damage and photoaging.

\section{What was learned from the study?}

A night cream containing melatonin, carnosine and Helichrysum italicum extract reduced skin damage caused by environmental factors and its nightly use improved clinical signs of aging and reduced skin irritation.

Use of rationally designed anti-aging formulations which leverage the skin's own defense and repair mechanisms can help limit the signs of age and photodamage.

\section{DIGITAL FEATURES}

This article is published with digital features to facilitate understanding of the article. You can access the digital features on the article's associated Figshare page. To view digital features for this article go to https://doi.org/10.6084/m9. figshare.12876359.

\section{INTRODUCTION}

As an organ, the skin is unique in that it serves as the interface between the body and its external environment. As such, it is exposed to a variety of potentially damaging insults that must be effectively controlled in order to maintain cellular homeostasis. With age and prolonged exposure to these extrinsic factors, the skin, particularly on exposed areas like the face, gradually accumulates damage that manifests itself as dryness, wrinkling, laxity and pigmentary changes.

Ultraviolet (UV) radiation alone has been estimated to be responsible for about $80 \%$ of facial aging [1]; however the impact of other components of solar radiation and air pollution cannot be underestimated. Like UV, the visible and infrared (IR) components of solar radiation, as well as constituents of air pollution, cause oxidative stress that drives the skin aging process [2-5]. In a study of 400 Caucasian women aged 70-80 years, air pollution was found to be associated with a $20 \%$ increase in pigment spots on the forehead and cheeks [6]. Repeated exposure to solar radiation, pollution and even the overuse of harsh cosmetics can also compromise the barrier function of the skin, making it become more reactive or sensitive [7]. In the USA, over $40 \%$ of the population consider themselves as having sensitive skin, and rates in other populations are similar [7].

Skin, however, is capable of self-repair, and its regeneration can be stimulated by the application of cosmetic formulations designed to reverse the effects of age and skin damage. Remarkably, skin's ability to do this appears to be greatest at night, suggesting that there is a natural physiological shift in skin from daytime protection to night-time repair [8]. Logically then, anti-aging skin care regimens might be most effective in adopting a similar pattern, with daytime protection (i.e., by application of full-spectrum sunscreens) complemented with night-time use of products designed to augment skin's recovery and repair. Considering this we have developed a cream for use at night (referred to here as Night Cream; NC) that contains a combination of active ingredients designed to stimulate the skin's own defense and repair mechanisms and combat the clinical signs of aging.

In order to demonstrate the anti-aging and skin soothing benefits of NC we undertook a holistic approach. We examined the ability of $\mathrm{NC}$ to augment the recovery of ex vivo human skin explants following oxidative stress induced by UVA and IR radiation and pollution and to protect against blue light (BL)-induced 
hyperpigmentation. We also evaluated the clinical efficacy and acceptability of NC under normal conditions of use and determined its ability to reduce cutaneous irritation in subjects with sensitive skin.

\section{METHODS}

\section{Test Products}

The investigational product (NC) used in all studies was an oil-in-water emulsion containing niacinamide, hyaluronic acid (HA), carnosine, matricins peptides, melatonin and an extract of the Mediterranean flowering plant Helichrysum italicum.

\section{Ex Vivo Study}

\section{Skin Explants}

Human skin explants of an average diameter of $12 \mathrm{~mm}( \pm 1 \mathrm{~mm})$ were prepared from surgical skin residues of abdominal skin obtained from Caucasian women (35-63 years of age; Fitzpatrick phototype III). Three explants from the same donor were used per exposure group.

All explants used in this study were obtained from surgical residues after written informed consent from the donor and in full accordance with the Declaration of Helsinki and article L.1245-2 of the French Public Health Code. The latter does not require any prior authorization by an ethics committee for use of surgical waste.

\section{Product Application}

To determine the recovery effect of NC following exposure of the skin explants to UVA, IR and pollution, we applied NC immediately after exposure of the explants to the environmental aggressor. To assess its protective effect against $\mathrm{BL}, \mathrm{NC}$ was applied $30 \mathrm{~min}$ prior to exposure. In both situations, NC was evenly applied to the surface of the explant with a small spatula at a final concentration of $2 \mathrm{mg} / \mathrm{cm}^{2}$. Untreated control batches did not receive any treatment except for renewal of the culture media.

\section{Stress Exposures}

UVA Explants were placed in $1 \mathrm{~mL}$ of Hank's Balanced Salt Solution (HBSS) in 12-well culture plates and irradiated with $4.5 \mathrm{~J} / \mathrm{cm}^{2}$ of UVA $(\lambda \max =365 \mathrm{~nm})$ using a Vilber Lourmat RMX$3 \mathrm{~W}$ UV simulator (Vilber Lourmat, Marne-laVallée, France), once daily for 5 consecutive days.

Pollution Explants were exposed to a mixture of polycyclic aromatic hydrocarbons and heavy metals for $1.5 \mathrm{~h}$ on days 3 and 5 as described previously [9].

IR Explants were exposed to a single $720 \mathrm{~J} /$ $\mathrm{cm}^{2}$ dose of IR radiation $(760-3000 \mathrm{~nm})$ on day 4 using an infrared lamp (Dr. Fischer $1000 \mathrm{~W}$ 235 V SK15; Dr. Fischer, Diez/Lahn, Germany) filtered through water and a visible light filter (HEBO IR 760; HEBO Specialglas, Aalen, Germany). To avoid heat effects during IR exposure, explants were maintained at $37-39^{\circ} \mathrm{C}$ using a culture media refreshing system.

$B L$ Explants were irradiated with $63.75 \mathrm{~J} / \mathrm{cm}^{2}$ of BL (420-480 nm; $\lambda \max 460 \mathrm{~nm})$ using a Solarbox ${ }^{\circledR}$ visible light simulator (Laboratoire Bio-EC, Longjumeau, France) on day 0, day 1, day 4 and day 5.

Non-exposed control explants were kept in $1 \mathrm{~mL}$ of HBSS in the dark for the same duration of time as stress-exposed explants.

\section{Histology}

Twenty-four hours after the final exposure, explants were frozen or fixed in buffered formalin, and sections were prepared using standard techniques.

Type I collagen immunostaining was performed on $7-\mu \mathrm{m}$-thick frozen sections using a polyclonal anti-collagen I antibody (PSO47 Monosan; Sanbio, Uden, the Netherlands). Cell nuclei were counterstained with propidium iodide. 8-Hydroxydeoxyguanosine (8-OHdG), aryl hydrocarbon receptor (AHR), matrix-metalloproteinase-1 (MMP-1) and HA immunostaining was performed on 5 - $\mu$ m-thick paraffin sections using the following primary antibodies: monoclonal anti-8-OHdG antibody (ref. 50-MOG; Gentaur, Kampenhout, Belgium); monoclonal anti-AHR antibody (ref. MA1-514; Thermo Fisher Scientific, Waltham, MA, USA); polyclonal anti-MMP-1 antibody (ref. M4696; 
Sigma Aldrich, St. Louis, MO, USA); biotinylated anti-hyaluronan binding protein antibody (bHABP, ref. AMS.HKD-BC41; Amsbio LLC, Abingdon, UK). Staining was revealed using the Vector VIP Peroxidase Substrate Kit (Vector Laboratories, Burlingame, CA, USA).

Melanin was visualized in $5-\mu \mathrm{m}$-thick paraffin sections using Fontana-Masson staining.

\section{Image Analysis}

The area of the skin positive for the marker of interest was determined in nine images per condition (3 replicates per explant; 3 explants per condition/stressor) using Cell ${ }^{\wedge} \mathrm{D}$ software (Olympus Life Science, Waltham, MA, USA). The mean \pm standard error (SEM) of the stained surface percentage for each treatment was compared to the equivalent untreated condition using Student's $t$-test. A $p$ value $<0.05$ was considered to be significant.

\section{Clinical Studies}

Four prospective, single-center, open-label, noncomparative studies were performed to evaluate: (1) skin hydration kinetics and transepidermal water loss (TEWL); (2) comedogenicity; (3) anti-aging efficacy; and (4) skin calming effects in subjects with sensitive skin. Characteristics of the study populations are shown in Table 1.

Due to the cosmetic nature of $\mathrm{NC}$, ethics committee approval was not required. All clinical studies were performed after written informed consent from the subjects was received, and in full accordance with the Declaration of Helsinki (1964) and its subsequent amendments, and following COLIPA guidelines for the Evaluation of the Efficacy of Cosmetic Products [10]. Good Clinical Practice was maintained throughout the studies.

\section{Hydration Kinetics and TEWL}

Hydration kinetics and TEWL were assessed in 24 subjects aged 19 to 65 years with dry skin. $\mathrm{NC}$ was applied to one forearm (randomized for each subject), with the other forearm used as an untreated control. Skin hydration of both forearms was evaluated using a Corneometer ${ }^{\circledR}$
CM825 probe connected to a Cutometer ${ }^{\circledR}$ Dual MPA 580 (Courage + Khazaka electronic $\mathrm{GmbH}$, Cologne, Germany) at $1 \mathrm{~h}(1 \mathrm{H}), 2 \mathrm{H}, 4 \mathrm{H}$, $8 \mathrm{H}$ and $12 \mathrm{H}$. TEWL in the treated and untreated forearms was evaluated by Tewameter ${ }^{\circledR}$ TM 300 (Courage + Khazaka electronic $\mathrm{GmbH}$, Cologne, Germany) at $1 \mathrm{H}, 2 \mathrm{H}, 4 \mathrm{H}, 8 \mathrm{H}$ and $12 \mathrm{H}$.

\section{Comedogenicity}

Comedogenicity was assessed in 31 women aged 35 to 50 years with mixed to oily skin with comedones and signs of aging. NC was applied once nightly for 28 consecutive nights. Skin acceptability and compatibility and its effect on comedones and non-inflammatory lesions was determined by dermatologist evaluation according to the method of Lucky et al. [11].

\section{Anti-Aging Efficacy}

Anti-aging efficacy was evaluated in 31 female volunteers aged 40 to 60 years with wrinkle grade II-V (Bazin wrinkle scale), photopigmentation grade II-IV (Bazin photopigmentation scale) and slight sagging. NC was applied once nightly for 84 consecutive nights. Efficacy was determined through evaluation of (1) periocular wrinkles by the AEVA-HE system (Eotech, Marcoussis, France); (2) skin firmness and elasticity by Cutometer ${ }^{\circledR}$ Dual MPA 580 (Courage + Khazaka electronic GmbH, Cologne, Germany); (3) UV and brown spots reduction by the VISIA-CA imaging and skin analysis system (Canfield Scientific, Parsippany, NJ, USA); (4) and digital images of the subject's face. All parameters were evaluated at baseline (D0) and on days 28, 56 and 84 (D28, D56, D84, respectively) post treatment initiation. In addition, an Investigator Global Assessment (IGA) and a Patient Global Assessment (PGA) were conducted on D28, D56 and D84 using a 7-point scale, where $-2=$ significantly worse; $-1=$ slightly worse; $0=$ no change; $1=$ slightly improved; $2=$ moderately improved; $3=$ significantly improved; $4=$ completely improved. A subject self-assessment regarding the efficacy of NC was performed on D84 using a questionnaire with a 4-point Likert scale, ranging from 1 (strongly disagree) to 4 (strongly agree). 
Table 1 Characteristics of clinical study participants

\begin{tabular}{lllll}
\hline $\begin{array}{l}\text { Characteristics of study } \\
\text { participants }\end{array}$ & $\begin{array}{l}\text { Study 1 (hydration } \\
\text { kinetics and TEWL) }\end{array}$ & $\begin{array}{l}\text { Study } 2 \\
\text { (comedogenicity) }\end{array}$ & $\begin{array}{l}\text { Study } \mathbf{3} \text { (anti- } \\
\text { aging efficacy) }\end{array}$ & $\begin{array}{l}\text { Study 4 (skin } \\
\text { calming effect) }\end{array}$ \\
\hline No. of subjects & 24 & 31 & 31 & 30 \\
Female, $n(\%)$ & $23(95.8)$ & $31(100)$ & $31(100)$ & $26(86.6)$ \\
Male, $n(\%)$ & - & - & $4(13.3)$ \\
Mean age \pm SD, years & $49.9 \pm 13.7(19-65)$ & $41.3 \pm 4.8$ & $50.6 \pm 5.2$ & $53.1 \pm 11.5$ \\
$\quad($ min-max) & & $(35-50)$ & $(43-59)$ & $(21-67)$ \\
Fitzpatrick skin phototype, $n(\%)$ & - & - & $1(3.3)$ \\
I & - & $5(16.3)$ & $5(16.1)$ & $3(10.0)$ \\
II & $3(12.5)$ & $24(77.4)$ & $21(67.7)$ & $26(86.6)$ \\
III & $21(87.5)$ & $2(6.4)$ & $3(9.7)$ & \\
IV & - & & & $30(100)$ \\
Skin type, $n(\%)$ & & - & $4(12.9)$ & - \\
Dry & $24(100)$ & - & $6(19.4)$ & - \\
Normal & - & $26(83.9)$ & $21(67.7)$ & - \\
Combined & - & $5(16.1)$ & - & $30(100)$ \\
Oily & - & $31(100)$ & $6(19.4)$ & \\
Skin condition, $n(\%)$ & & & & \\
Sensitive & & & & \\
\hline
\end{tabular}

$S D$ Standard deviation, $T E W L$ transepidermal water loss

\section{Skin Calming Effect}

Calming efficacy was evaluated in 30 volunteers aged 21 to 67 years with dry and reactive skin and known positivity to the lactic acid stinging test [12]. Stinging was induced on D0, D7 and D28 by rubbing a cotton pad impregnated with $10 \%$ lactic acid onto one half of the nasolabial fold (randomized for each subject). The other half was used as a control by rubbing a pad impregnated with $0.9 \% \mathrm{NaCl}$. NC was applied by the subject themselves nightly for 28 nights by gentle digital massage until complete absorption. Stinging was evaluated on D0 (prior to NC treatment) and on D7 and D28 (with NC treatment) by: (1) subjective evaluation using a 4-point scale, where $0=$ absent; $1=$ light; $2=$ moderate; 3 =significant; (2) clinical signs (dryness, erythema, desquamation and roughness) by the investigator using the Overall Dry Skin Score in the case of the dryness evaluation and the specified symptoms sum score for the other clinical symptoms [13]; (3) feeling of discomfort by subjective assessment using a 4-point scale, where $0=$ absent; $1=$ slight; $2=$ moderate; 3 = severe. Improvement was also measured by IGA and PGA scores using a 6-point scale, where $-1=$ worsening; $0=$ no change; $1=$ mild improvement; $2=$ moderate improvement; 3 = good improvement; $4=$ very good improvement. In addition, efficacy was evaluated through a questionnaire as described previously. 


\section{Statistical Analysis}

Values are expressed as the mean \pm standard deviation. A Wilcoxon test for paired samples was performed to evaluate changes between the data obtained at baseline (OH/DO) and at each time point. Differences were considered to be significant at $p<0.05$. Statistical analysis was performed using SPSS software (version 20.0; IBM Corp., Chicago, IL, USA).

\section{RESULTS}

\section{Ex Vivo Study}

\section{Recovery from Environmental Damage}

Application of NC after exposure to UVA, pollution and IR significantly reduced skin damage in explants caused by oxidative stress (Fig. 1):

$U V$ The levels of 8-OHdG, an oxidized nucleoside of DNA, were $49 \%$ lower $(p<0.01$; Fig. 1a) and type I collagen was $19 \%$ higher $(p<0.05$; Fig. $1 b)$ in NC-treated explants exposed to UVA than in untreated explants.

Pollution The levels of the pollution-activated transcription factor AHR were 96\% lower $(p<0.01$; Fig. 1c) and type I collagen 68\% higher $(p<0.01$; Fig. 1d) in NC-treated explants than in untreated explants.

IR The levels of MMP-1, the endopeptidase principally responsible for degradation of type I collagen, were $35 \%$ lower in the epidermis $(p<0.01$; Fig. 1 e) and $14 \%$ lower in the papillary dermis $(p>0.05$; Fig. 1e) of NC-treated explants compared to untreated explants.

Blue light Melanin levels in the basal layer of the epidermis were also reduced by $36 \%$ $(p<0.05$; Fig. 1f) in explants treated with NC prior to BL exposure.

\section{Effect on HA Levels}

Following application of NC for 5 consecutive days, HA levels in the epidermis were increased by $70.1 \%(p<0.01)$ relative to untreated skin. Chronic exposure to UVA reduced HA levels in the papillary dermis by $29.9 \%(p<0.05)$, but $\mathrm{NC}$ reversed this effect, with HA levels increased by $83.6 \%(p<0.01)$ relative to untreated skin.

\section{Clinical Studies}

\section{Effect on Hydration Kinetics and TEWL}

In subjects with dry skin $(n=24)$, skin hydration was significantly increased from basal values $(0 \mathrm{H})$ at $1 \mathrm{H} \quad(+64.4 \% ; p<0.05), 2 \mathrm{H}$ $(+66.4 \% ; p<0.05), 4 \mathrm{H}(+63.6 \% ; p<0.05), 8 \mathrm{H}$ $(+48.9 \% ; \quad p<0.05)$ and $12 \mathrm{H} \quad(+33.2 \%$; $p<0.05)$ post-NC treatment (Table 2). TEWL $(n=24)$ was significantly reduced from basal values at $1 \mathrm{H}$ after treatment with $\mathrm{NC}(-10.0 \%$; $p<0.05)$. Hydration and TEWL values of untreated control skin were unchanged at all time points (Table 2).

\section{Comedogenicity}

After 28 days of application $(n=31), \quad \mathrm{NC}$ reduced the number of open comedones by $0.9 \%(p>0.05)$ and the number of closed comedones by $15.9 \% \quad(p<0.05)$. The total number of non-inflammatory lesions was reduced by $16.1 \%(p<0.05)$.

\section{Effect on Wrinkles}

Night Cream had a positive effect on the appearance of Crow's feet wrinkles in women with overt signs of aging ( $n=30$; Fig. $2 \mathrm{a})$. The mean number of wrinkles was significantly reduced after 28 days $(-11.1 \% ; p<0.05)$, 56 days $\quad(-10.9 \% ; \quad p<0.05)$, and 84 days $(-18.9 \% ; p<0.05)$ (Table 3$)$. Wrinkle volume was reduced on D56 $(-8.1 \% ; p<0.05)$ and D84 $(-14.8 \% ; p<0.05)$ (Table 3$)$, and the average depth of these wrinkles was reduced by $6.9 \%$ on D56 $(p<0.05)$ and by $7.7 \%$ on D84 $(p<0.05$; Table 3).

\section{Effect on Skin Roughness}

There was an overall trend towards improvement of skin roughness in the malar region, with $\mathrm{Ra}$ (arithmetic mean roughness) reduced by $4.4 \%$ at D56 $(p<0.05)$ and by $4.2 \%$ at D84 $(p<0.05)$ (Table 3$)$. Rz (mean depth roughness) was significantly reduced at D56 (-3.7\%; $p<0.05$ ) (Table 3).

\section{Effect on Brown and UV Spots}

The number of brown spots was reduced by $5.5 \%$ at D28 $(p<0.05), 3.4 \%$ at D56 $(p<0.05)$ 
A

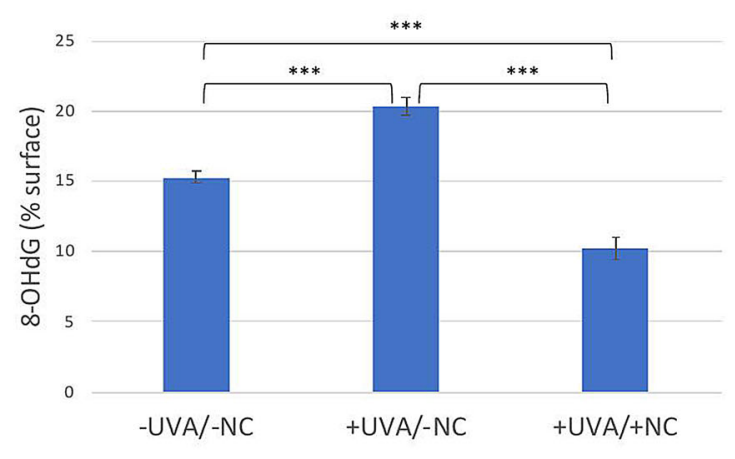

C

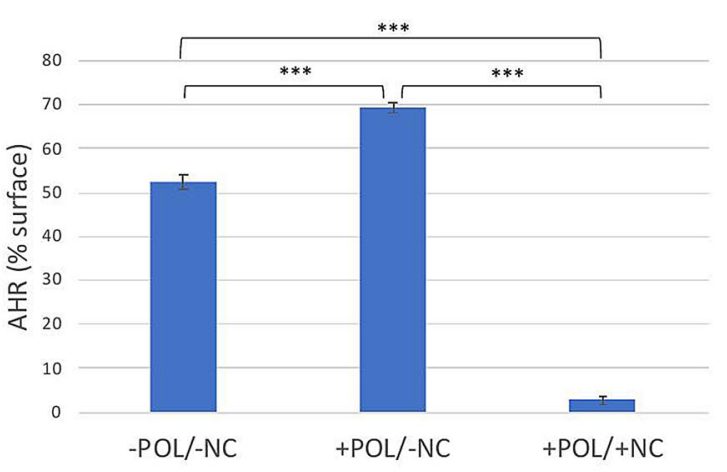

E

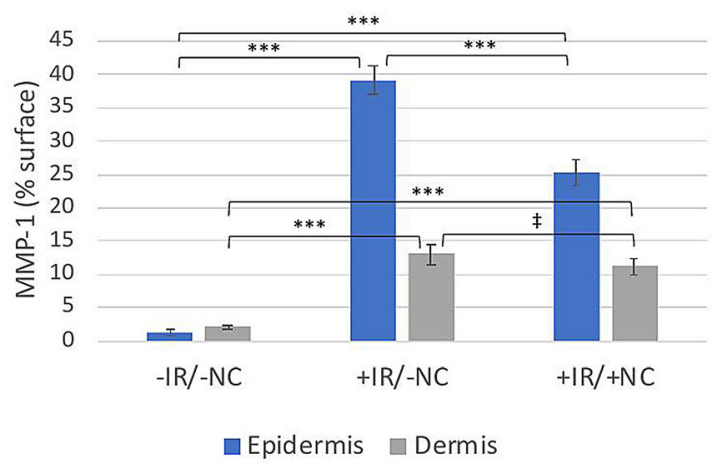

Fig. 1 Night Cream $(N C$; oil-in-water emulsion containing niacinamide, hyaluronic acid, carnosine, matricins peptides, melatonin and an extract of the Mediterranean flowering plant Helichrysum italicum) augments the recovery of skin from environmental stress. a 8-Hydroxydeoxyguanosine $(8-O H d G)$ expression levels following ultraviolet A $(U V A)$ exposure. b type I collagen levels following UVA exposure. c Aryl hydrocarbon receptor $(A H R)$ expression levels following exposure to pollution $(P O L)$. d type I collagen levels following exposure to POL.
B

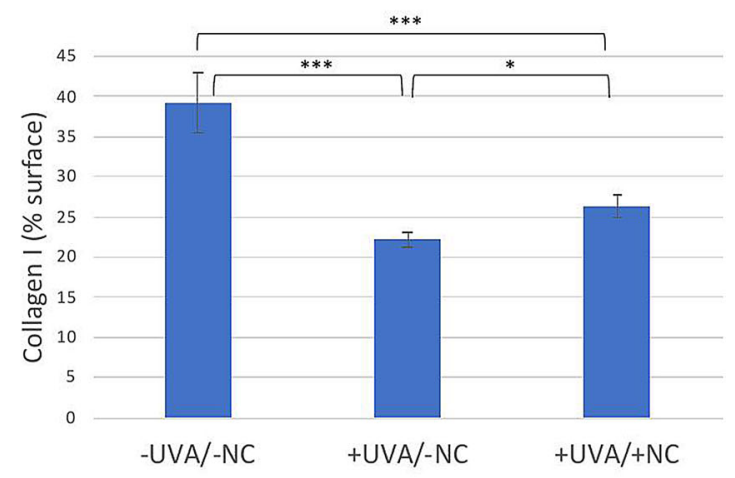

D

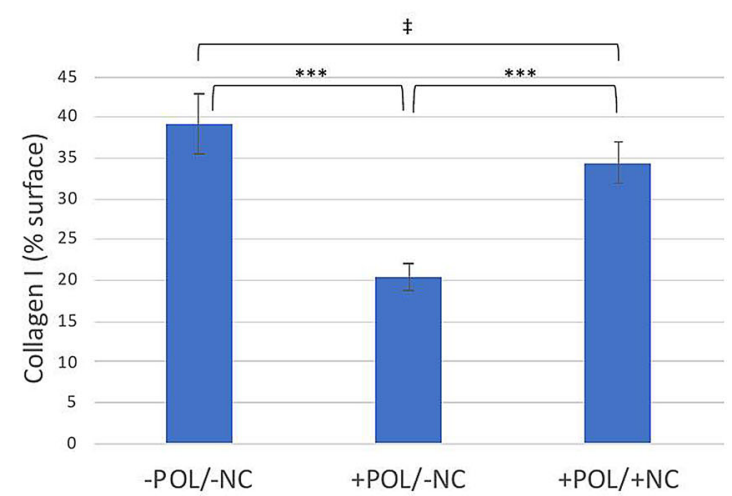

$\mathrm{F}$

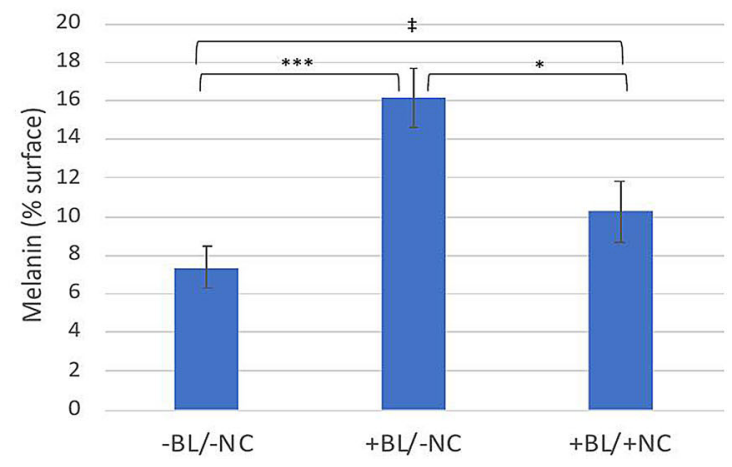

e Matrix-metalloproteinase-1 (MMP-1) expression levels in the epidermis (blue bars) and dermis (gray bars) following exposure to infrared $(I R)$. $\mathbf{f}$ Melanin levels in the basal layer of the epidermis following exposure to blue light $(B L)$. Graphs show mean area of expression ( \pm standard error of the mean $[S E M]$ ) in 9 independent images per condition. All experiments were performed $24 \mathrm{~h}$ after the final exposure. Significant difference at ${ }^{* * *} p<0.01$; ${ }^{*} p<0.05 ;{ }^{*} p>0.05$ 
Table 2 Hydration kinetics and transepidermal water loss of Night Cream-treated skin $(n=24)$

\begin{tabular}{|c|c|c|c|c|c|c|c|}
\hline \multirow[t]{2}{*}{ Parameter } & \multirow[t]{2}{*}{ Treatment groups } & \multicolumn{6}{|c|}{ Time point ${ }^{a}$} \\
\hline & & $\overline{\mathbf{0 H}}$ & $1 \mathrm{H}$ & $2 \mathrm{H}$ & $4 \mathrm{H}$ & $8 \mathrm{H}$ & $12 \mathrm{H}$ \\
\hline \multirow[t]{2}{*}{ Hydration (AU) } & $\mathrm{NC}$ & $36.6 \pm 2.4$ & $60.2 \pm 6.4^{*}$ & $60.9 \pm 6.5^{*}$ & $59.9 \pm 8.0^{*}$ & $54.5 \pm 6.8^{*}$ & $48.8 \pm 6.9^{*}$ \\
\hline & Control & $35.6 \pm 2.8$ & $36.1 \pm 3.2$ & $36.3 \pm 3.0$ & $35.6 \pm 2.6$ & $35.9 \pm 3.0$ & $35.6 \pm 3.7$ \\
\hline \multirow[t]{2}{*}{ TEWL $\left(\mathrm{g} / \mathrm{h} / \mathrm{m}^{2}\right)$} & $\mathrm{NC}$ & $7.6 \pm 1.4$ & $6.8 \pm 1.7^{*}$ & $7.1 \pm 1.3$ & $7.5 \pm 1.5$ & $7.6 \pm 1.5$ & $7.9 \pm 2.2$ \\
\hline & Control & $7.7 \pm 1.9$ & $7.8 \pm 1.9$ & $7.5 \pm 1.6$ & $7.6 \pm 1.7$ & $7.5 \pm 2.1$ & $7.6 \pm 2.1$ \\
\hline
\end{tabular}

Values in table are given as the mean \pm SD

${ }^{*}$ Significantly different at $p<0.05$ vs. basal /baseline $(0 \mathrm{H})$ values

$A U$ arbitrary units, $N C$ oil-in-water emulsion containing niacinamide, hyaluronic acid, carnosine, matricins peptides, melatonin and an extract of the Mediterranean flowering plant Helichrysum italicum

${ }^{a} 0 \mathrm{H}$, Basal value/baseline; $1 \mathrm{H}, 2 \mathrm{H}, 4 \mathrm{H}, 8 \mathrm{H}, 12 \mathrm{H}, 1,2,4,8$ and $12 \mathrm{~h}$, respectively, after application of $\mathrm{NC}$ to treated forearms (controls: no treatment to forearm)

and $3.2 \%$ at D84 $(p<0.05)$ (Table 3; Fig. 2b). The area of brown spots was reduced by $4.1 \%$ at D28 ( $p<0.05), 2.6 \%$ at D56 $(p<0.05)$ and 3.9\% at D84 $(p<0.05)$ (Table 3). Similarly, the number of UV spots were reduced by $13.2 \%$ at D28 $(p<0.05), 9.6 \%$ at D56 $(p<0.05)$ and $7.8 \%$ at D84 $(p<0.05)$ (Table 3$)$. UV spot area was reduced by $14.9 \%$ at D28 $(p<0.05), 7.1 \%$ at D56 $(p<0.05)$ and $12.3 \%(p<0.05)$ at D84 $(p<0.05)$ (Table 3; Fig. 2c). The effects of NC were less significant at D56 and D84 than at D28 for both brown and UV spots due to the influence of the sun, as these times were at the height of summer in Southern Europe.

\section{Effect on Skin Firmness and Elasticity}

Skin firmness (R0) was increased after 28 days $(+9.2 \% ; p<0.05), 56$ days $(+15.3 \% ; p<0.05)$ and 84 days $(+22.4 ; p<0.05)$ of use (Table 3$)$. Similarly, skin elasticity (R2) was increased by $4.2 \%$ at D28 $(p>0.05), 12.9 \%$ at D56 $(p<0.05)$, and $7.7 \%$ at D84 $(p<0.05)$ (Table 3$)$.

\section{Investigator and Patient Global Assessment}

The IGA and PGA scores increased across the study period from 0.8 and 1.42 , respectively, at D28 (slightly improved) to 1.6 and 1.97, respectively, at D84 (moderately improved; Table 3).

\section{Skin Calming Efficacy}

Night Cream significantly reduced the lactic acid stinging score in subjects with reactive skin $(n=30)$ after $7(-42.8 \% ; p<0.01)$ and 28 days $(-85.1 \% ; p<0.01)$ of use (Table 4$)$, with 86.7 and $96.7 \%$ of patients, respectively, reporting an improvement to their stinging score at these timepoints. Significant improvements to clinical signs (i.e. dryness, roughness, desquamation and erythema) and feelings of discomfort were also observed (Table 4). IGA and PGA scores increased from 0.9 and 1.0, respectively, at D7 (slightly improved), to 2.0 and 2.4, respectively, at D28 (between moderate and good improvement; Table 4).

\section{Subject Questionnaire}

With respect to the anti-aging qualities of NC, subjects reported an improvement to their skin quality, better hydration, fewer wrinkles and visible spots, and their skin as being smoother, more homogenous and more luminous, in accordance with the results described previously (Table 5). With respect to its skin calming properties, $86.7 \%$ agreed that their skin was less sensitive and calmer (Table 6).

\section{Cutaneous Acceptability}

No safety or adverse events related to NC were reported during any of the studies, and no 
A

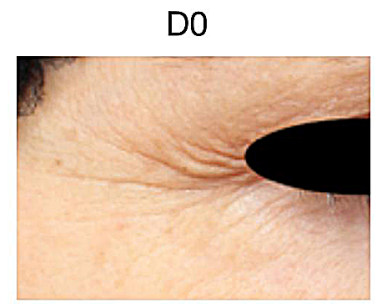

B

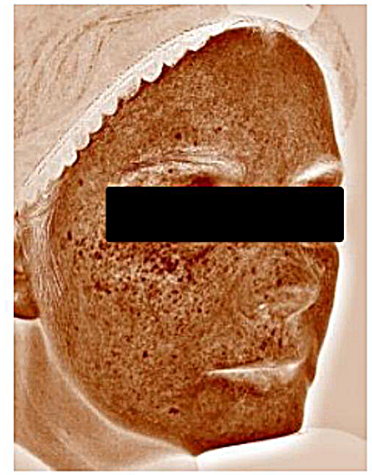

C
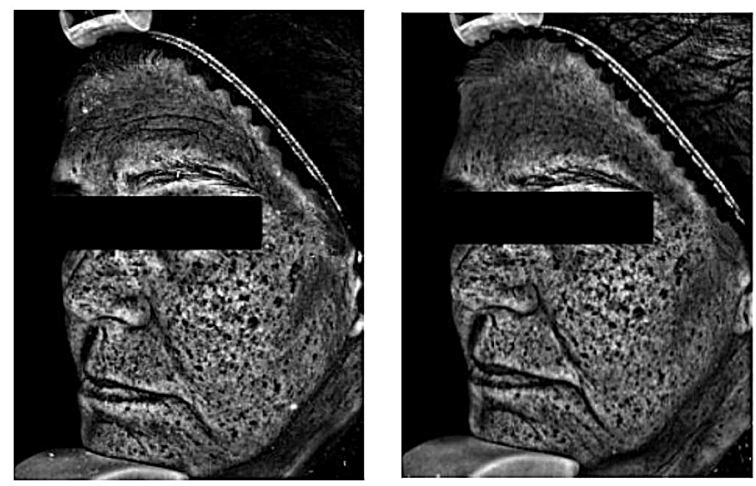

Fig. 2 Anti-aging effect of NC. a Evolution of crow's feet wrinkles at baseline $(D O)$ and at 28, 56 and 84 days (D28, $D 56, D 84$, respectively) of NC application. b Evolution of brown spots at D0, D28, D56 and D84. Images captured by the VISIA-CA imaging and skin analysis system.

sensations of discomfort were reported by any of the study participants.

\section{DISCUSSION}

While the natural aging process cannot be stopped, the impact of extrinsic factors on the skin can be mitigated. Daily use of sunscreens and cosmetics that protect against the harmful effects of UV radiation are an important
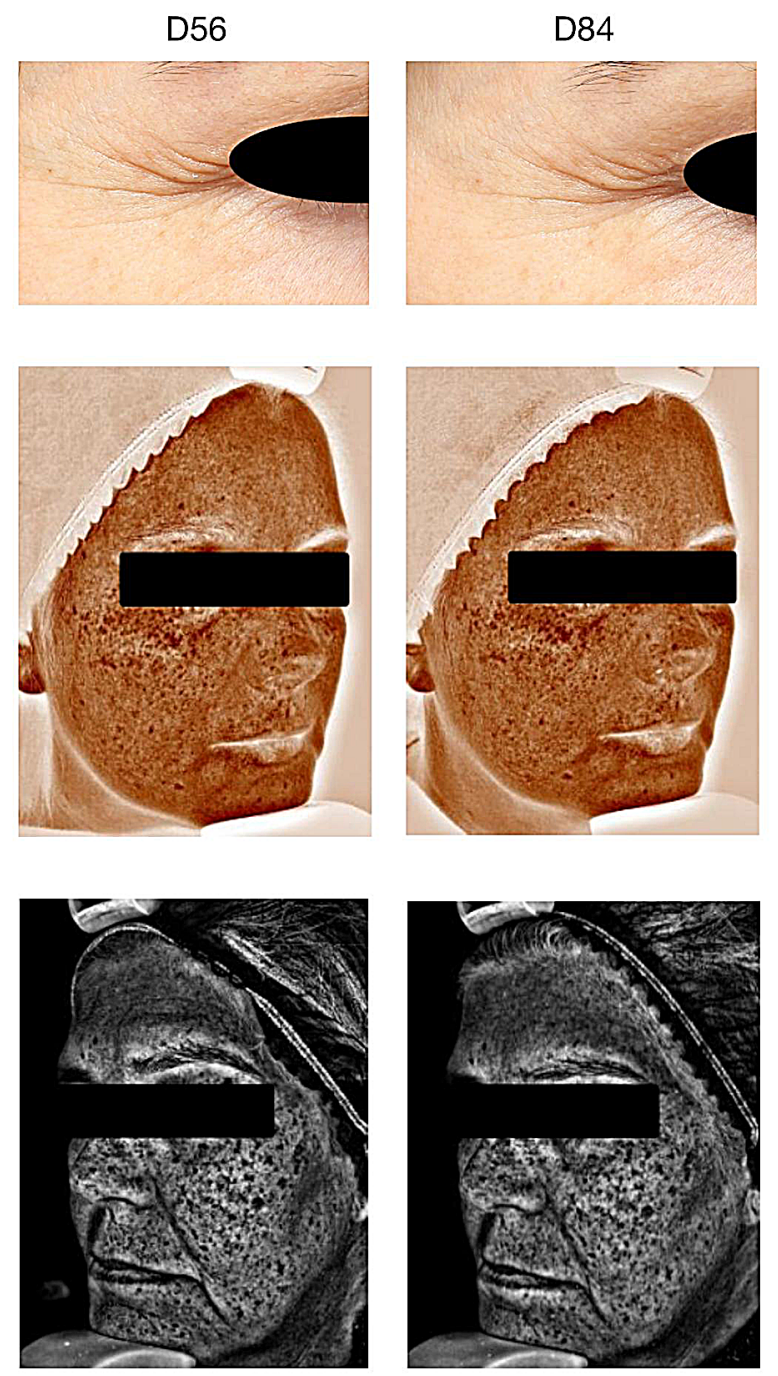

c Evolution of UVA spots at D0, D28, D56 and D84. Images captured by VISIA-CA

component of an effective anti-aging regimen, but it has become clear that UV protection is not enough. Other components of solar radiation, urban pollution, stress and lack of proper sleep all invoke biological responses akin to those of UV that cause lasting skin damage. We show here that application of NC following exposure to UVA, IR and pollution can significantly reduce these effects. Moreover, NC was also able to mitigate the pro-pigmentary effects of BL. 
Table 3 Anti-aging efficacy of Night Cream $(n=31)$

\begin{tabular}{|c|c|c|c|c|}
\hline \multirow[t]{2}{*}{ Parameters } & \multicolumn{4}{|l|}{ Time point ${ }^{a}$} \\
\hline & D0 & D28 & D56 & D84 \\
\hline Wrinkle count $(n)$ & $6.6 \pm 2.3$ & $5.7 \pm 2.2^{*}$ & $5.8 \pm 2.5^{*}$ & $5.3 \pm 2.2^{*}$ \\
\hline Wrinkle volume $\left(\mathrm{mm}^{3}\right)$ & $1.04 \pm 0.71$ & $1.04 \pm 0.84$ & $0.94 \pm 0.71^{*}$ & $0.92 \pm 0.69^{*}$ \\
\hline Wrinkle depth (mm) & $0.047 \pm 0.01$ & $0.047 \pm 0.01^{*}$ & $0.045 \pm 0.01^{*}$ & $0.045 \pm 0.01^{*}$ \\
\hline $\mathrm{Ra}(\mathrm{mm})$ & $0.020 \pm 0.005$ & $0.020 \pm 0.004$ & $0.019 \pm 0.003^{*}$ & $0.019 \pm 0.003^{*}$ \\
\hline $\mathrm{Rz}(\mathrm{mm})$ & $0.07 \pm 0.02$ & $0.06 \pm 0.01$ & $0.06 \pm 0.01^{*}$ & $0.06 \pm 0.01$ \\
\hline Brown spot count $(n)$ & $327.4 \pm 31.3$ & $309.2 \pm 35.0^{*}$ & $315.7 \pm 33.9^{*}$ & $315.9 \pm 28.6^{*}$ \\
\hline Brown spot area (\% pixels) & $60.3 \pm 10.0$ & $57.8 \pm 10.0^{*}$ & $58.5 \pm 9.1^{*}$ & $57.7 \pm 9.1^{*}$ \\
\hline UV spot count $(n)$ & $254.1 \pm 76.5$ & $225.4 \pm 78.5^{*}$ & $231.2 \pm 79.2^{*}$ & $231.3 \pm 77.1^{*}$ \\
\hline UV spot area (\% pixels) & $30.5 \pm 12.3$ & $24.9 \pm 11.4^{*}$ & $27.0 \pm 12.5^{*}$ & $25.5 \pm 11.7^{*}$ \\
\hline $\mathrm{R} 0(\mathrm{~mm})$ & $0.30 \pm 0.07$ & $0.27 \pm 0.07^{*}$ & $0.25 \pm 0.06^{*}$ & $0.23 \pm 0.05^{*}$ \\
\hline R2 (\%) & $0.56 \pm 0.10$ & $0.58 \pm 0.08$ & $0.63 \pm 0.10^{*}$ & $0.60 \pm 0.08^{*}$ \\
\hline IGA & - & $0.77 \pm 0.43$ & $0.87 \pm 0.34$ & $1.61 \pm 0.56$ \\
\hline PGA & - & $1.42 \pm 1.18$ & $1.65 \pm 1.14$ & $1.97 \pm 1.20$ \\
\hline
\end{tabular}

Values in table are given as the mean $\pm \mathrm{SD}$

*Significantly different at $p<0.05$ vs. basal /baseline (D0) values

$I G A$ Investigator Global Assessment, $P G A$ Patient Global Assessment, $R a$ arithmetic mean roughness, $R z$ mean depth roughness, $R O$ skin firmness, $R 2$ skin elasticity

a D0, Basal value/baseline; D28, D56, D84, 28, 56 and 84 days of NC application

Table 4 Calming effect of Night Cream $(n=30)$

\begin{tabular}{llll}
\hline Parameters & Time point & \\
\cline { 2 - 4 } & D0 & D7 & D28 \\
\hline Stinging score & $1.7 \pm 0.7$ & $0.8 \pm 0.4^{* * *}$ & $0.3 \pm 0.4^{* * *}$ \\
Dryness score & $2.6 \pm 0.5$ & $2.1 \pm 0.5^{* * *}$ & $1.5 \pm 0.4^{* * *}$ \\
Roughness score & $2.1 \pm 0.7$ & $1.8 \pm 0.7^{* * *}$ & $1.2 \pm 0.6^{* * *}$ \\
Desquamation score & $0.4 \pm 0.6$ & $0.2 \pm 0.4^{* * *}$ & $0.1 \pm 0.3^{* * *}$ \\
Erythema score & $0.7 \pm 0.6$ & $0.5 \pm 0.5^{* * *}$ & $0.2 \pm 0.3^{* * *}$ \\
Feeling of discomfort & $3.0 \pm 0.8$ & $2.3 \pm 0.8$ & $1.5 \pm 0.7$ \\
IGA & - & $0.9 \pm 0.3$ & $2.0 \pm 0.7$ \\
PGA & - & $1.0 \pm 0.5$ & $2.4 \pm 1.2$ \\
\hline
\end{tabular}

Values in table are given as the mean $\pm \mathrm{SD}$

${ }^{* * *}$ Significantly different at $p<0.01$ vs. basal /baseline (D0) values 
Table 5 Percentage of positive responses to self-assessment subjective questionnaire on the anti-aging efficacy of Night Cream after 84 days of application $(n=31)$

\begin{tabular}{ll}
\hline Questionnaire & \% Positive responses \\
\hline Product provides hydration & 93.5 \\
Product reduces signs of stress and fatigue & 90.3 \\
Skin is softer & 93.5 \\
Skin is smoother & 93.5 \\
Product improves the overall aspect of skin & 90.3 \\
Product enhances my sense of well-being & 93.5 \\
Fewer dark spots after using product & 80.6 \\
Product lightens darker spots on skin & 77.4 \\
No new dark spots since using the product & 96.8 \\
Skin is more homogenous and has a more even tone & 90.3 \\
Skin is more luminous & 93.5 \\
Reduces the appearance of fine lines around the eye & 87.1 \\
Reduces the appearance of crow's feet wrinkles & 87.1 \\
Reduces the appearance of forehead wrinkles & 88.9 \\
Wrinkle in general are less visible & 83.9 \\
Deep wrinkles are reduced & 77.4 \\
Sagging is reduced & 87.1 \\
Restores the firmness of the skin & 87.1 \\
Visibly tightened skin & 90.3 \\
Face oval is redrawn & 87.1 \\
Face volume is resculpted & 83.9 \\
\hline Product provides a rejuvenating effect & 87.1 \\
\hline postive r.
\end{tabular}

A positive response was considered as either 4: strongly agree or 3: slightly agree

Clinically, NC helped reverse some of the key signs of age and photodamage. Skin hydration levels were significantly increased for $12 \mathrm{~h}$ and TEWL reduced from basal levels within $1 \mathrm{~h}$ of application of NC. This is likely the result of not only the moisturizing properties of the skin conditioning agents and emollients in the formulation, but also the inclusion of niacinamide and HA, both of which help reinforce the skin barrier and increase hydration levels [14, 15]. Our ex vivo studies demonstrated that HA levels in the epidermis and dermis of UVA-exposed skin were boosted by 70.1 and $83.6 \%$, respectively. Additionally, NC-treated skin was not only smoother, a direct reflection of its restorative effect on the skin barrier, but also more homogenous, with fewer less UV and brown spots. Niacinamide is thought to be central to this effect by blocking the transfer of melanin-containing melanosomes from melanocytes to keratinocytes [16]. 
Table 6 Percentage of positive responses to self-assessment subjective questionnaire on the skin calming activity of night cream after 38 days of application $(n=30)$

\begin{tabular}{ll}
\hline Questionnaire & \% Positive responses \\
\hline Product reduces signs of stress and fatigue & 83.3 \\
I feel my skin is calmer & 86.7 \\
Freshness effect when I apply the product & 100 \\
Skin is protected and reinforced & 93.3 \\
More de-stressed skin & 90.0 \\
The product enhances my sense of well-being & 93.3 \\
My skin is less sensitive & 86.7 \\
The redness of my skin is reduced & 76.7 \\
\hline
\end{tabular}

A positive response was considered as either 4: Strongly agree or 3: Slightly agree

NC contains melatonin, one of skin's primary antioxidant defence systems. Melatonin is a potent scavenger of reactive oxygen species (ROS) [17] that also upregulates antioxidative enzymes in skin [18], thereby explaining its efficacy in reducing levels of 8-OHdG and limiting MMP-1 expression and collagen degradation in our ex vivo studies. Melatonin levels, as well as those of its cellular receptors, decline with age, contributing to a natural decline in the antioxidative capacity of the skin [19]. There is also evidence to suggest that dysregulation of the normal circadian rhythm as a result of the age-associated decline in melatonin leads to increased ROS production and oxidative stress [20], so NC, in boosting melatonin levels, should help maintain normal cellular homeostasis. As well as protecting skin from the damaging effects of UV [21, 22], melatonin and its metabolites have also been demonstrated to have other anti-aging benefits for skin, including reducing inflammation, promoting tissue regeneration and preserving mitochondrial function [23]. Since NC also contains the matricins peptide palmitoyl tripeptide-1 that stimulates collagen synthesis [24], normal collagen homoeostasis will also be maintained, helping limit wrinkle development. Notably, crow's feet wrinkles were significantly reduced with NC-treatment, and these effects were more pronounced the longer the study went on.
As well as environmental agents, dietary factors, especially the consumption of too much sugar, are also thought to cause wrinkles [25]. The factors responsible for this are advanced glycation end-products (AGEs) that are formed when glucose and fructose bind to and crosslink collagen and elastin fibers within the dermis [26]. Cross-linking of these proteins alters skin's mechanical properties and prevents their repair following damage $[25,26]$. With the inclusion of carnosine, which we have previously shown to limit AGE formation [25], NC should also reduce AGE levels.

$\mathrm{NC}$ reduced cutaneous irritation in subjects with sensitive skin. Impaired barrier function is thought to be one of the underlying causes of this [7], so the improved dryness, roughness and desquamation scores following application of $\mathrm{NC}$, providing evidence of a positive effect on the epidermal barrier, helps explain why lactic acid-induced stinging responses were reduced. Erythema and feelings of discomfort were also reduced, likely, at least in part, due to the antiinflammatory action of niacinamide and the matricins peptide palmitoyl tetrapeptide-7 $[24,27]$. NC also contains an extract of the Mediterranean flowering plant Helichrysum italicum which has been shown to have anti-inflammatory activity as well as photoprotective effects [28]. These actions are thought to be due to its high flavonoid content which scavenges 
free radicals and inhibits histamine production and proinflammatory cytokine and prostaglandin release in irritated skin [29].

NC was very well tolerated in multiple populations with different skin types, including subjects with reactive and atopic skins: the absence of any skin reactions or adverse events after more than 4000 applications of NC over the four separate clinical studies are testament to this. Of course, consumer perception of a product is as important as any objective change in skin aging parameter, so the positive responses in terms of the efficacy of NC to the user questionnaires are significant. This is even more pertinent for a product like NC where adherence and prolonged nightly use translate to more significant anti-aging and skin calming benefits, as well as an enhanced sense of wellbeing.

Objective evaluation of NC, however, is obviously limited by the absence of any control arms or treatment blinding, as well as any evaluation of the effects of NC on markers of skin damage in vivo.

\section{CONCLUSIONS}

In clinical studies involving a total of 117 individuals and supported by ex vivo histological evaluations, NC significantly reduced skin damage caused by environmental factors and its nightly use improved the clinical signs of age and photodamage, as well as reducing cutaneous reactivity in subjects with sensitive skin. NC was well tolerated and proved suitable for use by individuals with all skin types.

\section{ACKNOWLEDGEMENTS}

The authors thank all subjects for their participation in the study, to Laurent Peno-Mazzarino of Laboratoire Bio-EC, Longjumeau, France who performed the ex vivo study, and to PhD Trials ${ }^{\circledR}$, Lisbon, Portugal who performed the clinical studies.
Funding. All studies and the journal's Rapid Service Fee were funded by ISDIN, the manufacturer of the formulation under study.

Authorship. All named authors meet the International Committee of Medical Journal Editors (ICMJE) criteria for authorship for this article, take responsibility for the integrity of the work as a whole, and have given their approval for this version to be published.

Authorship Contributions. Anthony Brown, Sonia Aladren and Mridvika Narda designed the study. Anthony Brown wrote the manuscript. Corinne Granger, Sonia Aladren and Mridvika Narda critically reviewed the manuscript. All authors have read and approved the final manuscript.

Disclosures. Corinne Granger, Sonia Aladren and Mridvika Narda are employees of ISDIN, the manufacturer of the formulation under study. Anthony Brown is a paid consultant to ISDIN.

Compliance with Ethics Guidelines. Ex Vivo Study: All explants used in this study were obtained from surgical residues after written informed consent from the donor and in full accordance with the Declaration of Helsinki and article L.1245-2 of the French Public Health Code. The latter does not require any prior authorization by an ethics committee for use of surgical waste. Clinical Studies: Due to the cosmetic nature of $\mathrm{NC}$, ethics committee approval was not required. All clinical studies were performed after written informed consent from the subjects was received, and in full accordance with the Declaration of Helsinki (1964) and its subsequent amendments, and following COLIPA guidelines for the Evaluation of the Efficacy of Cosmetic Products [10]. Good Clinical Practice was maintained throughout the studies.

Data Availability. Data sharing is not applicable to this article as no datasets were generated or analyzed during the current study. 
Open Access. This article is licensed under a Creative Commons Attribution-NonCommercial 4.0 International License, which permits any non-commercial use, sharing, adaptation, distribution and reproduction in any medium or format, as long as you give appropriate credit to the original author(s) and the source, provide a link to the Creative Commons licence, and indicate if changes were made. The images or other third party material in this article are included in the article's Creative Commons licence, unless indicated otherwise in a credit line to the material. If material is not included in the article's Creative Commons licence and your intended use is not permitted by statutory regulation or exceeds the permitted use, you will need to obtain permission directly from the copyright holder. To view a copy of this licence, visit http://creativecommons.org/licenses/by$\mathrm{nc} / 4.0 /$.

\section{REFERENCES}

1. Friedman O. Changes associated with the aging face. Facial Plast Surg Clin North Am. 2005;13: 371-80.

2. Watson REB, Gibbs NK, Griffiths CEM, Sherratt MJ. Damage to skin extracellular matrix induced by UV exposure. Antioxid Redox Signal. 2014;21:1063-77.

3. Liebel F, Kaur S, Ruvolo E, Kollias N, Southall MD. Irradiation of skin with visible light induces reactive oxygen species and matrix-degrading enzymes. J Invest Dermatol. 2012;132:1901-7.

4. Cho S, Shin MH, Kim YK, et al. Effects of infrared radiation and heat on human skin aging in vivo. J Investig Dermatology Symp Proc. 2009;14:15-9.

5. Lodovici M, Bigagli E. Oxidative stress and air pollution exposure. J Toxicol. 2011;2011:487074.

6. Vierkötter A, Schikowski T, Ranft U, et al. Airborne particle exposure and extrinsic skin aging. J Invest Dermatol. 2010;130:2719-26.

7. Duarte I, Silveira JEPS, Hafner MFS, Toyota R, Pedroso DMM. Sensitive skin: review of an ascending concept. An Bras Dermatol. 2017;92:521-5.

8. Dong K, Goyarts EC, Pelle E, Trivero J, Pernodet N. Blue light disrupts the circadian rhythm and create damage in skin cells. Int J Cosmet Sci. 2019;41: 558-62.

9. Narda M, Bauza G, Valderas P, Granger C. Protective effects of a novel facial cream against environmental pollution: in vivo and in vitro assessment. Clin Cosmet Investig Dermatol. 2018;11:571-8.

10. COLIPA. COLIPA guidelines. Efficacy evaluation of cosmetic products. 2008. https://www. cosmeticseurope.eu/files/4214/6407/6830/

Guidelines_for_the_Evaluation_of_the_Efficacy_of_ Cosmetic_Products_-_2008.pdf. Accessed 20 May 2020.

11. Lucky AW, Barber BL, Girman CJ, Williams J, Ratterman J, Waldstreicher J. A multirater validation study to assess the reliability of acne lesion counting. J Am Acad Dermatol. 1996;35:559-65.

12. Ding D-M, Tu Y, Man M-Q, et al. Association between lactic acid sting test scores, self-assessed sensitive skin scores and biophysical properties in Chinese females. Int J Cosmet Sci. 2019;41: 398-404.

13. Serup J. EEMCO guidance for the assessment of dry skin (xerosis) and ichthyosis: clinical scoring systems. Ski Res Technol. 1995;1:109-14.

14. Mohammed D, Crowther JM, Matts PJ, Hadgraft J, Lane ME. Influence of niacinamide containing formulations on the molecular and biophysical properties of the stratum corneum. Int J Pharm. 2013;441:192-201.

15. Papakonstantinou E, Roth M, Karakiulakis G. Hyaluronic acid: a key molecule in skin aging. Dermatoendocrinol. 2012;4:253-8.

16. Hakozaki T, Minwalla L, Zhuang J, Chhoa M, Matsubara A, Miyamoto K, et al. The effect of niacinamide on reducing cutaneous pigmentation and suppression of melanosome transfer. Br J Dermatol. 2002;147:20-31.

17. Tan D-X, Chen LD, Poeggeler B, Manchester LC, Reiter R. Melatonin: a potent endogenous hydroxyl radical scavenger. Endocr J. 1993;1:57-60.

18. Fischer TW, Kleszczynski K, Hardkop LH, Kruse N, Zillikens D. Melatonin enhances antioxidative enzyme gene expression (CAT, GPx, SOD), prevents their UVR-induced depletion, and protects against the formation of DNA damage (8-hydroxy-2'deoxyguanosine) in ex vivo human skin. J Pineal Res. 2013;54:303-12.

19. Dong K, Goyarts E, Rella A, Pelle E, Wong YH, Pernodet N. Age Associated decrease of MT-1 melatonin receptor in human dermal skin 
fibroblasts impairs protection against UV-induced DNA damage. Int J Mol Sci. 2020;21:2.

20. Matsui MS, Pelle E, Dong K, Pernodet N. Biological rhythms in the skin. Int J Mol Sci. 2016;17:2.

21. Janjetovic Z, Jarrett SG, Lee EF, Duprey C, Reiter RJ, Slominski AT. Melatonin and its metabolites protect human melanocytes against UVB-induced damage: involvement of NRF2-mediated pathways. Sci Rep. 2017;7:1274.

22. Skobowiat C, Brożyna AA, Janjetovic $\mathrm{Z}$, et al. Melatonin and its derivatives counteract the ultraviolet $\mathrm{B}$ radiation-induced damage in human and porcine skin ex vivo. J Pineal Res. 2018;65:e12501.

23. Day D, Burgess CM, Kircik LH. Assessing the potential role for topical melatonin in an antiaging skin regimen. J Drugs Dermatol. 2018;17:966-9.

24. Schagen SK. Topical peptide treatments with effective anti-aging results. Cosmetics. 2017;4:16. https://www.mdpi.com/2079-9284/4/2/16
25. Narda M, Peno-Mazzarino L, Krutmann J, Trullas C, Granger C. Novel facial cream containing carnosine inhibits formation of advanced glycation endproducts in human skin. Skin Pharmacol Physiol. 2018;31:324-31.

26. Danby FW. Nutrition and aging skin: sugar and glycation. Clin Dermatol. 2010;28:409-11.

27. Ungerstedt JS, Blömback M, Söderström T. Nicotinamide is a potent inhibitor of proinflammatory cytokines. Clin Exp Immunol. 2003;131:48-52.

28. Facino RM, Carini M, Mariani M, Cipriani C. Antierythematous and photoprotective activities in guinea pigs and in man of topically applied flavonoids from Helichysum italicum G. don. Acta Therapeutica. 1988;14(4):323-45.

29. Antunes Viegas D, Palmeira-de-Oliveira A, Salgueiro L, Martinez-de-Oliveira J, Palmeira-de-Oliveira R. Helichrysum italicum: from traditional use to scientific data. J Ethnopharmacol. 2014;151:54-655. 